\title{
Vivienda de los ferrocarrileros en México. Apuntes para comprender su tipología en lo urbano y lo rural
}

\section{Andrés Armando Sánchez Hernández ${ }^{1}$}

Primera versión recibida en: 24 abril, 2019

Última versión recibida en: 24 septiembre, 2019

\section{Resumen}

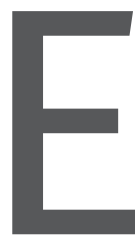

$n$ este texto se hace un acercamiento a un tema poco estudiado: el de la vivienda de los trabajadores del ferrocarril en México, pues tradicionalmente se ha tratado la vivienda de los trabajadores de las industrias textiles, asociada a conjuntos y zonas de producción, y por lo tanto, al patrimonio de la cultura industrial.

En ese sentido se tratan varias particularidades con respecto a otros ti-

1 Docente-investigador de la Facultad de Arquitectura de la BUAP; participa en la Licenciatura en Urbanismo y Diseño Ambiental y en la Maestría en Arquitectura, con especialidad en Conservación del Patrimonio Edificado, en la BUAP. Perfil de docentes SEP-PRODEP desde 2005, Miembro del Padrón de investigadores VIEP-BUAP; 2018-2022. Responsable del cuerpo académico Estudios Territoriales y Urbanos (CA-117) desde 2015.

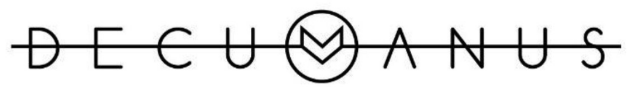

REVISTA INTERDISCIPLINARIA SOBRE ESTUDIOS URBANOS pos de vivienda, incluso, porque los vagones eran utilizados para habitarse. Asimismo, la vivienda diseñada con fundamentos espaciales y materiales en las zonas aledañas respondían a los procesos de diseño y de las vanguardias de finales del siglo XIX y siglo $X X$, propios de la influencia de la industria, en general, de la modernidad.

El punto de partida de la interpretación radica en el análisis tipológico, lo que permite reconocer las características, materiales, sistemas constructivos, y en general, las condiciones de la vivienda en los lugares establecidos. Este tipo de vivienda era empleada por los trabajadores en los vagones, y eran viviendas rodantes que unian a los ferrocarriles y les permitían viajar por diversos rumbos del país.

Se concluye que hubo diversos formatos, muchos de los que ahora son parte del patrimonio de la cultura industrial ferrocarrilera y que pueden apreciarse como parte del sitio o conjunto asociado a las estaciones, talle- 
res, etcétera, y la vivienda puede verse como parte de un paisaje cultural.

Palabras clave: vivienda, trabajadores, ferrocarriles, vanguardias.

\section{Summary}

In this text an approach is made to a little treated topic: the housing of railroad workers in Mexico, since traditionally they have treated the housing of the workers of the textile industries, which were associated to sets and production areas, and therefore, to the heritage of industrial culture.

In that sense it is a question of several peculiarities with respect to other types of housing, even because the cars could be used to inhabit. Likewise, the house designed with space and material foundations in the surrounding areas responded to the design processes and the avant-garde of the late nineteenth and twentieth centuries, typical of the influence of industry, in general, of modernity.

The starting point of the interpretation lies in the typological analysis, which allows us to recognize the characteristics, materials, construction systems, and, generally, the conditions of the dwelling in the established places. Based on the fact that this type of housing was used by workers in the wagons, and they were mobile homes that linked the railroads and allowed them to travel in many directions through the country.

It is concluded that there were various formats, many of which are now part of the railroad industrial culture heritage and can be seen as part of the site or set associated with stations, and workshops, besides, housing can be seen as part of a landscape cultural.

Keywords: housing, workers, railways, vanguards.

\section{Introducción}

El objetivo de este documento es el mostrar el contexto ideológico, tecnológico y social con que se definió la presencia de la vivienda de los trabajadores de los ferrocarriles. La primera razón: forma parte de los múltiples valores del hoy, patrimonio histórico-cultural de la industria y, en específico, lo podemos reconocer conformado, igualmente, dentro del amplio panorama de lo tangible e intangible. Otra razón: permite alojar las actividades contemporáneas para el mismo uso u otros dependiendo de las dimensiones y condiciones físicas del o los inmuebles, concomitantes como bienes culturales, así como parte de los conjuntos dedicados a estaciones, talleres, etcétera. Por otra parte, se puede vincular a un tema análogo apreciable en torno al análisis y debate sobre la vivienda del siglo decimonónico, su evolución y debacle dentro de la arquitectura de la modernidad, propia del siglo $x x$, tema que ha sido de interés desde hace muchos años, particularmente, desde que apareció en la mente y acciones de los utopistas decimonónicos, y luego, entrado el siglo $\mathrm{XX}$, en los famosos congresos de los CIAM (Congresos Internacionales de Arquitectura Moderna, por sus siglas en francés) en Europa. En la actualidad, esta producción se analiza para conservarlo y quizás restaurarlo por su valor testimonial y, en general, dentro del amplio campo del patrimonio

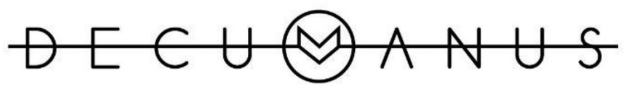

REVISTA INTERDISCIPLINARIA SOBRE ESTUDIOS URBANOS 
cultural, pero es imprescindible conocer sus condiciones y particularidades asociadas a niveles o puestos de trabajo de los trabajadores del ferrocarril, como a otras condiciones y contextos, tecnológicos, sociales, etcétera.

Otros trabajos, del mismo modo, exponen las condiciones de este tipo de vivienda, por ejemplo, Gisbert en su trabajo "Las viviendas inherentes a las estaciones de ferrocarril de vía estrecha en Valencia en la época de su construcción" (2015: 223) permite conocer un caso análogo de estudio y sustentar algunas reflexiones para su valoración y comparación. El siguiente párrafo expone una sección de su análisis tipológico en el contexto de España, pero que en muchos aspectos coinciden con el diseño de estaciones y vivienda en México:

La estación no estaba formalizada en base a [sic] una población determinada sino independiente de ella, a partir de unos estudios estadísticos de tráfico. Ello supone una estandarización de modelos, que pueden repetirse en diversas poblaciones de la misma categoría de una línea, en ambos o distintos momentos. Generalmente en las estaciones de cabeza o terminales se elaboraba el proyecto aparte [...]. Por consiguiente la vivienda inherente a la estación es el resultado de incorporar las necesidades funcionales de habitabilidad con los mínimos recursos distribuyéndoles en el interior de la edificación, respetando la configuración de la fachada [...] (p. 224).
Sin embargo, en muchos casos las estaciones tuvieron proyectos únicos para algunas ciudades o poblaciones, así mismo la vivienda tuvo diseños exprofeso en determinados lugares, teniendo según el rubro de tipo de habitante y ubicación en la empresa determinadas particularidades o privilegios de diseño y calidad en los materiales, sistemas constructivos y, en general en el aspecto tipológico.

El tema de la vivienda de los trabajadores es insoslayable al ámbito del patrimonio industrial. Recordemos en la Carta de Nizhny Tagil sobre el patrimonio industrial (2003) del TICCIH (The International Committe for the Conservation of Industrial Heritage) donde se expuso lo siguiente:

El patrimonio industrial se compone de los restos de la cultura industrial que poseen un valor histórico, tecnológico, social, arquitectónico o científico. Estos restos consisten en edificios y maquinaria, talleres, molinos y fábricas, minas y sitios para procesar y refinar, almacenes y depósitos, lugares donde se genera, se transmite y se usa energía, medios de transporte y toda su infraestructura, así como los sitios donde se desarrollan las actividades sociales relacionadas con la industria, tales como la vivienda, el culto religioso o la educación (p. 1).

Con base en ese texto se analizan las condiciones de la tipología de este tipo de vivienda al considerar su relación con lo histórico, tecnológico, social, arquitectónico o científico. La tipología, en ese marco valorativo, se identifica en los elementos que con-

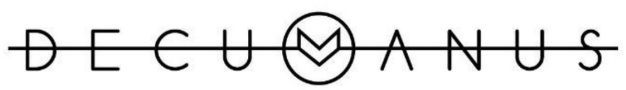

REVISTA INTERDISCIPLINARIA SOBRE ESTUDIOS URBANOS 
forman las viviendas de los ferrocarrileros, con elementos, en algunos casos análogos a la vivienda de otras formas de industria, pero con variaciones específicas según el nivel del rango laboral. Pero, si es única la vivienda de estos trabajadores en los vagones, que permitían recorrer distancias con sus familias, moviéndose anclados a los vagones del ferrocarril (véase imágenes 5 y 6 ).

En otro documento de carácter internacional, Principios de Dublin (2011) del ICOMOS-TICCIH, se reflejó esta idea sobre el patrimonio industrial en el Preámbulo:

El patrimonio industrial es extremadamente vulnerable $y$, a menudo se encuentra en riesgo; frecuentemente se pierde por falta de conciencia, documentación, reconocimiento y protección, pero también por tendencias económicas fluctuantes, percepciones negativas, cuestiones ambientales o a causa de su magnitud y complejidad. Sin embargo, al extender el ciclo de vida de las estructuras existentes y de su energía contenida, la conservación del patrimonio industrial construido, puede contribuir a la consecución de los objetivos del desarrollo sustentable en los planos local, nacional e internacional. Afecta los aspectos sociales del desarrollo, así como los físicos y ambientales y debe ser reconocida como tal (p. 1).

Por otra parte, y recientemente en la Carta de Sevilla (2018), aunque referida para Europa, algunos puntos son aplicables a otros países, se expone una serie de análisis y propuestas de valoración e incluso conservación, donde destaca las metodologías y herramientas para su estudio:

El objeto de estudio debe ser caracterizado en su multidimensionalidad histórica, morfológica, material, fenomenológica, social y simbólica mediante un enfoque decididamente transversal y multiescalar evitando el predominio de un enfoque disciplinar (p. 25).

Se puede comprender que la dimensión histórica de este tipo de viviendas en México, solo es un testimonio de una serie de actividades y manifestaciones de una cultura sui géneris. Por otra parte, la morfología se refiere a las condiciones y emplazamientos en que se ubicó la vivienda obrera, que fue diversa. Los materiales utilizados responden a periodos de la misma industria y la arquitectura, como se describe adelante. Fenomenológica, porque se configuraron interpretaciones de un tipo de vivienda con singularidades particulares como la vivienda en vagones, única en su tipo; relacionada con prácticas sociales y simbólicas.

Se plantean algunos elementos con que fue definiéndose la tipología de la vivienda de los ferrocarrileros en los lugares rurales y urbanos, en tanto, que en muchos de los casos fueron en lugares despoblados donde se fundaron algunas estaciones y los trabajadores tuvieron necesidades de alojarse en algún lado, por lo que les dieron viviendas. Espacios con factores que pueden verse desde la interpretación de la arquitectura como son los siguientes: el factor de uso, el expresivo,

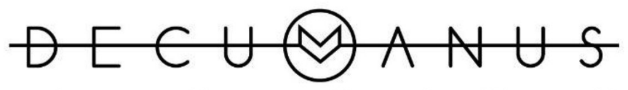

REVISTA INTERDISCIPLINARIA SOBRE ESTUDIOS URBANOS 
y el constructivo-estructural, además de su ejemplificación, en casos muy significativos, ante la diversidad de condiciones de las viviendas relacionadas a este tipo de trabajadores. Ello, nos lleva a identificar sus cualidades que les dieron origen, haciéndose un aspecto inseparable de sus condiciones como patrimonio: su autenticidad. ${ }^{2}$ Elementos que, además, pueden identificarse actualmente como parte del patrimonio cultural en sitios como elementos de reconocimiento, y condición metodológica de estudio y conservación. Por todo ello, este documento se divide en párrafos de lo general a lo particular y condiciones histórico-tecnológicas, que les dieron origen y evolucionaron.

Además, en este trabajo solo se realiza una ejemplificación, ante la diversidad de viviendas relacionadas a este tipo de trabajadores. En específico, en la modalidad de vivienda móvil, que caracterizó a toda una generación de formas de resolver la necesidad de habitación, y algunos casos de viviendas para los trabajadores establecidos en lugares de trabajo en diversas latitudes de México.

El diseño de las viviendas fueron diferentes, durante el siglo XIX respondían a la influencia de la Revolución Industrial, y con base en ello, hoy se les puede valorar como parte del patrimonio, incluso se les puede proteger con la Ley Federal de Monumentos y Zonas, Arqueológicos, Artísticos

2 Esta es una cualidad inseparable del patrimonio derivada de auténtico. Puede definir según el Diccionario de la Lengua Española (DLE): “auténtico,

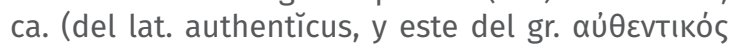
authentikós),1. adj. Acreditado de cierto y verdadero por los caracteres o requisitos que en ello concurren".

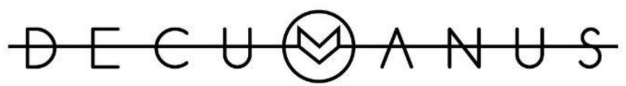

REVISTA INTERDISCIPLINARIA SOBRE ESTUDIOS URBANOS e Históricos, con que se fundamenta la acción legal y de defensa del INAH (Instituto Nacional de Antropología e Historia). Por otra parte, los que corresponden al periodo del siglo $\mathrm{XX}$, en los primeros años se les puede proteger con la Ley como monumento artístico, también se les puede defender con la idea y bajo los preceptos de valoración del patrimonio del siglo $\mathrm{xx}$.

En ese marco uno de los fundamentos recientes donde se reflejan los aspectos y formas-criterios de conservación es el Documento de Madrid (2011), organizado por el ICOMOS-España y que expone las condiciones con que se puede valorar:

El deber de conservar el patrimonio del siglo $x x$ tiene la misma importancia que la obligación de conservar el de otras épocas.

El patrimonio arquitectónico del siglo xx está en peligro debido a la falta de apreciación y cuidado. Una parte del mismo es ya irrecuperable, y otra, aún mayor, corre el mismo riesgo. Se trata de un patrimonio vivo que es esencial entender, definir, interpretar y gestionar adecuadamente para las generaciones futuras (p. 1).

En ese marco se aprecia la pertenencia a múltiples aspectos de la cultura y la sociedad este tipo de arquitectura y sus asociaciones históricas lo que permite comprender que está inmerso dentro de un contexto amplio, amén de su pertenencia a la cultura industrial ferrocarrilera cuya sede central se encuentra en el Museo Nacional de los Ferrocarriles Mexicanos en la Ciudad de Puebla, Puebla. 
En este artículo se desglosa mediante un estudio de sus antecedentes dentro del cual está el asunto del tema de la vivienda en la preocupación internacional, los ferrocarriles en México. Identifican una de sus particularidades en las viviendas fijas y rodantes de los trabajadores del camino de fierro, y se identifica alguna de su tipología, la vivienda de los ferrocarrileros en la ciudad de Puebla, una de sus modalidades y las conclusiones.

\section{Antecedentes}

Casi como un sueño, o algo inalcanzable, comenzaron algunas ideas para dotar de vivienda a los obreros; había sido desde la antigüedad, quizá no tengamos noticias o fechas y los lugares asociados al trabajo, muchas veces con condiciones ínfimas. Pero sí, en una vez que la Revolución Industrial se apoderaba de las ciudades antiguas, como de los lugares inhóspitos y rurales como en las grandes ciudades ya consolidadas, y con ello, primero en los slums o barrios casi ghettos con falta de servicios, y luego, cuando los utopistas comenzaron a idear su necesidad en las cercanías de los centros de trabajo. Por lo que valorar esas formas de vivienda en la actualidad forma parte de entender una serie de aspectos evolutivos, históricos, patrimoniales y sin duda, con un sentido social. Se trata de entender la tipología para poder conservarla, como parte del patrimonio cultural de la industria.

La vivienda obrera vio sus primeros espacios en la mente de los filántropos, humanistas y derivaciones de personajes de gran pensamiento progresis- ta y social que fueron moldeando los entornos en los conjuntos industriales, principalmente en los textiles. Por ello, en los primeros años -quizá idealistas-, hasta conformarse en verdaderas y acertadas realidades, una vez que fue de la aceptación de muchos empresarios y su presencia en diversos conjuntos industriales y latitudes, pudo verse. Además, se presentaron nuevos desafíos no solo tecnológicos y arquitectónicos, en general, una fascinante amplitud de niveles de la vida, el trabajo; derivándose, en lo que hoy, son múltiples estudios disciplinares.

En ese contexto, la aparición de las reflexiones sobre la vivienda de los obreros comenzó cuando los llamados utopistas decimonónicos (Robert Owen, Charles Fourier, Proudhon, Saint-Simon) quienes reflexionaron sobre las condiciones de los casi ghettos, o lugares improvisados en las cercanías de las primeras fábricas, con malolientes escenarios y las primeras humaredas y nubes de los chacuacos o chimeneas de las fábricas, que motivaron a pensar que la industria debería tomar un sentido más humanitario.

Por otro lado, en un ámbito también protagonista de la Revolución Industrial, y que cruzó diversas latitudes del mundo, dejando siempre sus típicas emanaciones de vapor de agua de gran blancura, y que formó parte del paisaje durante muchos años: el ferrocarril. Observado a su cruce por diversas miradas de los lugareños y pasajeros a través de sus ventanas -como rotafolios- que cambiaban panorama en cada segundo de su recorrido en la ciudad y lo rural, hasta que en México suspendió sus actividades dejando solamente en las vías el recuerdo.

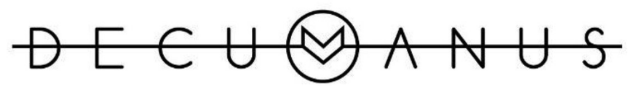

REVISTA INTERDISCIPLINARIA SOBRE ESTUDIOS URBANOS 
En ese contexto, diversas formas de industria, como la textil, el ferrocarril, y otras más, requirieron de vivienda para alojar a sus empleados; muchos de los que viajaban grandes distancias o, simplemente para tenerlos cerca y poder cumplir en sus horarios. Obreros/trabajadores que estaban diversificados dentro de los múltiples oficios y actividades desarrolladas dentro de producciones como los textiles; extracción de materiales, como la minería; y transportes, como los ferrocarriles.

Mucho del cual está relacionado con las herramientas, espacios, lugares, etcétera, y que forman parte de las zonas de producción o las colonias obreras. Por lo que su vinculación con los diversos elementos de lo natural y cultural, vistos como sitios mixtos, que la Unesco (siglas en inglés para la Organización de las Naciones Unidas para la Educación, Ciencia y la Cultura) definió hace apenas algunos años.

Por lo tanto, el llamado patrimonio industrial, como todos aquellos vestigios tangibles e intangibles de determinada sociedad y forma de producción, transformación de la materia, transporte, o generación de energía, en general, con la presencia de diversas formas de trabajo -algunas de ellas, definiendo a sus participantes como obreros-, se compone de un conjunto de valores, hoy vistos como histórico-culturales y que pueden analizarse desde la perspectiva del sitio o conjunto urbano o rural.

A lo cual, en este trabajo se da un primer acercamiento a reconocerlos en México, y por lo tanto, este trabajo tiene como objetivo principal plantear algunos elementos que fueron definiendo la tipología empleada en la vi- vienda de los ferrocarriles, ya que la vivienda obrera y de los trabajadores había estado como elemento de grandes reflexiones, análisis y atención disciplinar.

\section{a) El tema de la vivienda en la preocupación internacional}

Los primeros estudios sobre vivienda obrera, como tema de interés de disciplinas puntuales, fue en los arquitectónicos y urbanísticos. En específico, desde los primeros, hasta los últimos congresos de los CIAM (1929-1959), gran protagonista de esa hoy historia con el gran planteamiento del Existenzminimum o Extensium minimun (mínima extensión), respondiendo a los incipientes nuevos retos de los espacios en los lugares urbanizados. Pues, los lugares reducidos, principalmente en las grandes urbes, mostraban la necesidad de una adaptabilidad extrema, para ahorrar muchos aspectos, entre ellos, los materiales, lo económico en su edificación, como en su mantención. Nuevos territorios marcados por la ya, cada día, creciente explotación demográfica, y la necesidad de alojamiento de la población llegada del campo a la ciudad en la búsqueda de la tierra prometida, que buscaba empleo en las fábricas, principalmente.

Por ello, el sueño de mejores condiciones de la vivienda, tuvo gran resonancia en los arquitectos, muchos de ellos, de élites sociales y de lo que se convertía en un movimiento con gran eco durante el siglo Xx en diversas latitudes del mundo: la modernidad.

En México, la presencia de la vivienda para los obreros, es más tardía, en comparación con la europea. La pri-

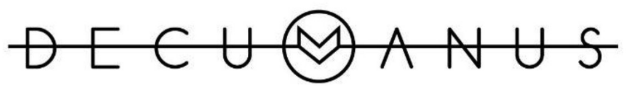

REVISTA INTERDISCIPLINARIA SOBRE ESTUDIOS URBANOS 
mera industria textil (movida con la fuerza hidráulica) inaugurada en 1834, con La Constancia Mexicana (LCM) donde pudieron tener viviendas integradas a los conjuntos industriales, hasta finales del siglo XIX y principios del XX -aunque ya había otras fábricas, quizá casi como obrajes, como la "Educación para niños", igualmente en la ciudad de Puebla, y otra, "La aurora yucateca" en Valladolid, Mérida. Pero la vivienda obrera se vio presente en sitios textiles como en Río Blanco, Veracruz: el conjunto más grande todo México, hacia principios del siglo Xx. También, en la segunda en dimensiones: la de Metepec, Atlixco, Puebla, y en la tercera en dimensiones: la más grande de la ciudad de Puebla, el Mayorazgo. Aunque en este sitios, hubo algunos "jacalones" realizados en el siglo XIX, pero en el siglo $\mathrm{xx}$ se realizaron otras viviendas, muy modernas y como la vanguardia en tipo de edificaciones.

Las viviendas dadas a los obreros en sitios textiles se veían con modelos ordenados, planificados, y dentro de un esquema que fue marcando élites laborales, pasando desde los obreros operarios, hasta las viviendas para empleados de confianza, con muchas más comodidades, con respecto a los antes mencionados. Pero, la vivienda estuvo en diversas formas de industria y actividades laborales, entre ellas, en los ferrocarriles.

En la generación actual, la vivienda obrera ha sido estudiada en específico sobre la vivienda de los sitios textiles, como testimonian algunos eventos como el Coloquio Villas Ouvriers, utopié or realité, efectuado en Familistère de Guise, Francia, en 1996. En México, algunos primeros rescates, igualmen- te testifican esa nueva valoración del patrimonio reutilizándolo con fines humanitarios y sociales, como el caso del conjunto de viviendas en San Manuel en Tlaxcala, emplazadas dentro de un conjunto de origen textil. Igualmente, sucede con los estudios y propuesta para el rescate de viviendas de obreros textiles, para el conjunto industrial de la Compañía Industrial de Atlixco, S. A. (CIASA), conocida también como Fábrica de Metepec. ${ }^{3}$ En este conjunto, el éxito no ha sido rotundo, porque la destrucción continúa, ante el poco arraigo mostrado por los habitantes y, por lo tanto, el éxito no ha sido el esperado en la conservación del mencionado lugar, ya que continúa la fase de deterioro y alteración ante la necesidad de nuevos espacios, el deterioro de los materiales, y la falta de una intervención adecuada de mantenimiento o preservación. Seguramente, sucediendo lo mismo en el ámbito de la vivienda de los trabajadores del ferrocarril, y otros destinos laborales más. Ya que muchas de ellas, se encuentran desprotegidas legalmente, tanto para el desconocimiento de sus propietarios, como de la sociedad en general.

\section{b) Los ferrocarriles en México}

La presencia de los ferrocarriles en México, al igual que en los diversos lugares del mundo, además de dejar un singular el silbido de sus locomotoras en los primeros años; se pudieron

3 Véase tesis de Licenciatura en Arquitectura "Recuperación del Caserío Obrero-histórica de Metepec, Atlixco, Pue", ganadora del premio "Manuel Toussaint" 2.o lugar como la mejor tesis de licenciatura en 1988, otorgada por el INAH.

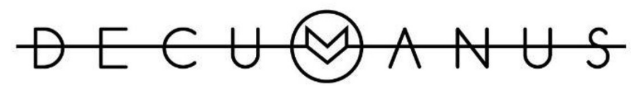

REVISTA INTERDISCIPLINARIA SOBRE ESTUDIOS URBANOS
Núm. 4. Vol. 4. Octubre 2018-Octubre 2019.

Instituto de Arquitectura, Diseño y Arte.

Universidad Autónoma de Ciudad Juárez. ISSN: 2448-900X 
apreciar diversas consecuencias, tanto dentro de las ciudades existentes, como en los lugares que recorrió.

El chamin le fer cuya forma de energía dada por el uso del agua (el vapor) permitió abrir brecha no sólo surcando por los paisajes europeos sino también en los mexicanos; desde bosques frondosos, desiertos, montañas, poblados, ciudades, etcétera. Teniendo repercusiones en la forma de intercambiar productos, viajar, y en general, dentro de la cultura. En específico, dentro de sus diversos aspectos económicos, sociales, y otras derivaciones más, durante varios periodos. Jorge Ramón Gómez Pérez (curador del Museo Nacional de los Ferrocarriles Mexicanos) considera: "La historia de los ferrocarriles mexicanos se puede dividir en tres grandes etapas bien definidas: la etapa de los antiguos ferrocarriles "históricos" (1837-1908), la etapa del predominio de los ferrocarriles nacionales de México (1908-1996), la etapa del sistema ferrocarrilero reprivatizado (1996- a la fecha)" (Gómez, 2004: 5). Muchas de esas infraestructuras se realizaron desde el siglo XIX (imágenes 1, 2).
Imagen 1. Acción de la creación de los Ferrocarriles México.

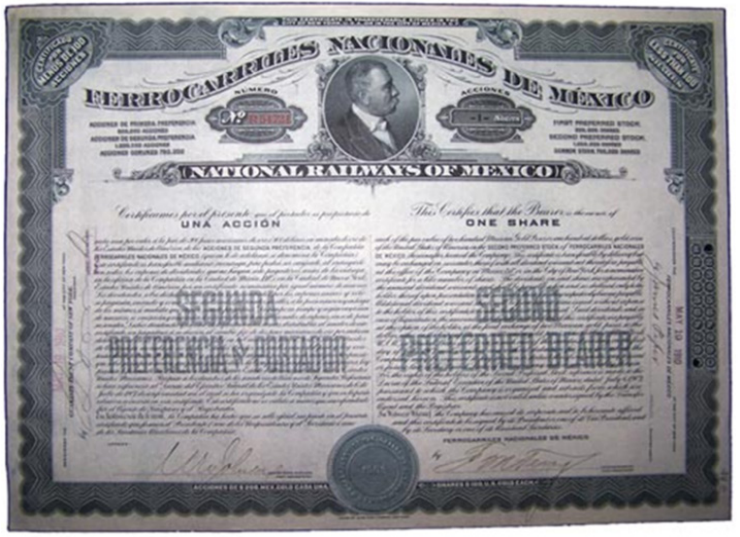

Fuente: CEDIF-MNFM- Conaculta

Imagen 2. Ferrocarril a su paso por la Estación Nacionales de El Mexicano de la Ciudad de Puebla.

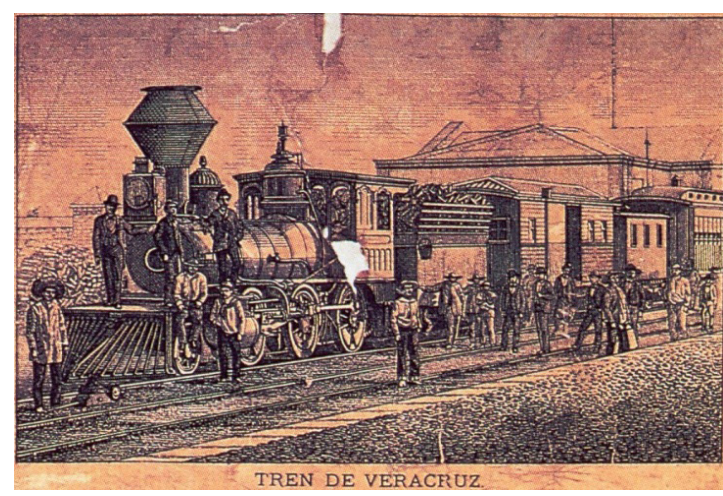

Fuente: Sección Plano realizado por Luis. C. Careaga, 1883. Archivo General de Puebla

(AGP)

Periodizaciones que, además se puede ver reflejada dentro de la tipología empleada en sus edificaciones que fueron siendo respuesta a los movimientos empleados dentro de la arquitectura. Asimismo, dentro de la forma de construir las locomotoras y equipamiento de las estaciones como de los talleres. En específico, se pueden apreciar dentro de la conforma- 
ción de la vivienda; como lo expone el siguiente autor:

En los talleres se realiza el trabajo de mantenimiento y reparación de máquinas y carros; en los patios se "arman" los trenes, o en otras palabras tiene lugar la clasificación y reclasificación de carros y formación de los trenes de carga; las terminales son el corazón de sistema ferroviario, ahí se encuentran los patios, los andenes, las oficinas, el despacho de boletos, bodegas, comedores y otros servicios; trenes donde se efectúa el manejo y operación del equipo de transporte, y vía, encargados de la construcción y mantenimiento de la infraestructura ferrocarrilera (Ebergenyi, 1986).

Imagen 3. Inauguración de la Estación del Ferrocarril de Puebla.

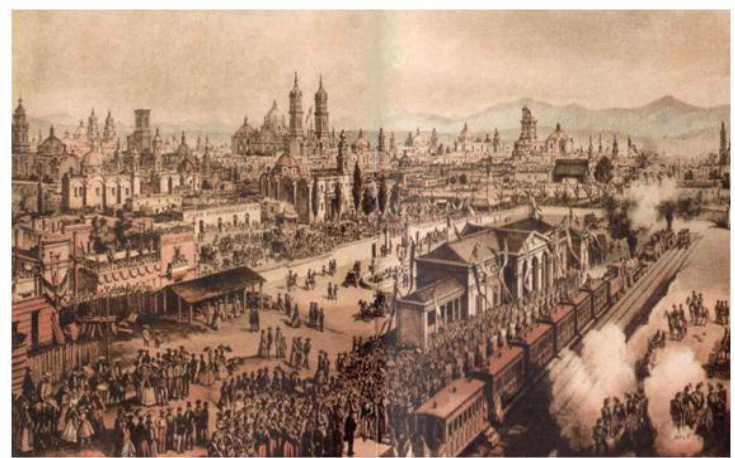

Fuente: Acuarela de Casimiro Castro. Portada Sinfonía del Vapor, MNFM-Conaculta.
Imagen 4. Plano de comunicaciones (carreteras y del ferrocarril) en Estación del Ferrocarril de Puebla. México en el siglo XIX.

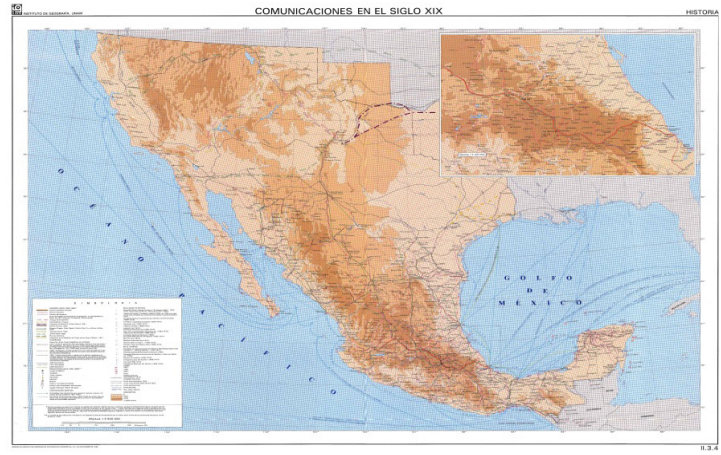

Fuente: www.igeogr.unam.mx/2012

\section{Viviendas fijas y rodantes de los trabajadores del "camino de fierro"}

Pero, una solución que rompió con todos los esquemas para resolver los espacios habitables fue la utilización de vagones para alojar al personal de los ferrocarriles en los llamados Carro campamento, que tenían la ventaja de poder movilizarse por las propias vías de fierro y adecuarse a las condiciones de los lugares elegidos por cuestiones laborales. Por lo que no era nada extraño observar "tendederos", "lavaderos", "jardincillos en macetas" en las afueras de ellos (véase imágenes 5 y 6$)$.

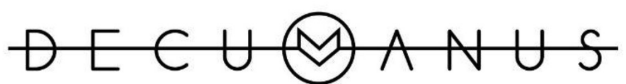

REVISTA INTERDISCIPLINARIA SOBRE ESTUDIOS URBANOS 
Imagen 5. Carro campamento.

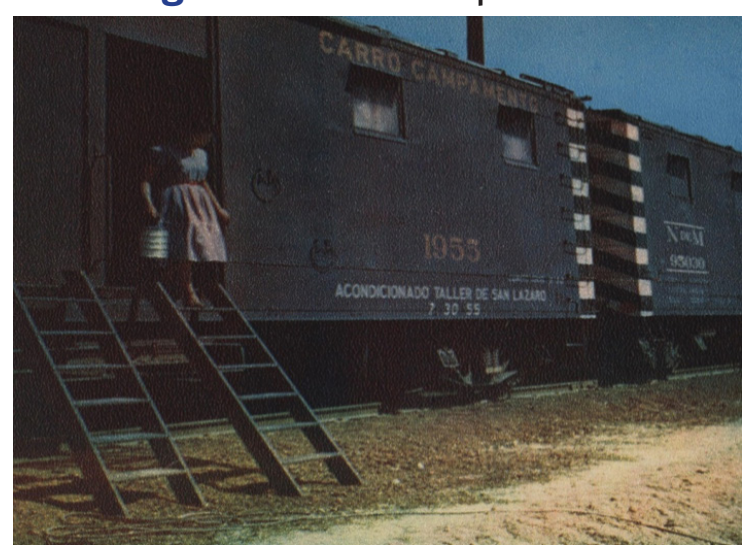

Fuente: Revista Ferronal, Fuente: Idem. México, abril, 1956, p. 33, CEDIF-MNFMConaculta.

Imagen 6. Carro campamento ídem. Ferrocarriles Nacionales de Archivo

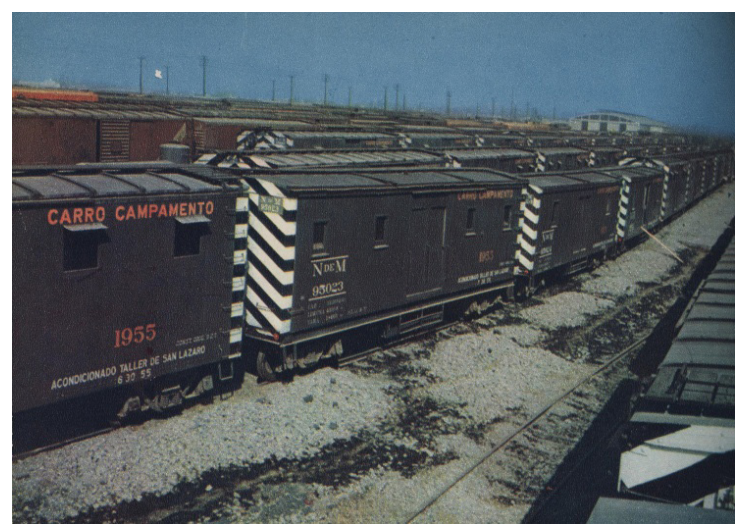

Por otro lado, la vivienda fija se ubicó en distintos rumbos del país específicamente en los talleres, como las realizadas en la misma época, pero de tipología diferente. Por ejemplo, la casa habitación para el Agente en la Estación Tres Cumbres, fechado en 1937, tiene condiciones muy similares en la forma y materiales de construir a los efectos ya mencionados de la Revolución Industrial, usando el típico dentado en ventanas, puertas y esquinas de los muros. Aunque esta vivienda era muy cómoda y amplia, resolvía sus espacios, diferenciando sus actividades unas de otras; así, podemos ver la cocina, comedor, estancia, baños (aseos) y un vestíbulo que daba acceso. Todos esos espacios ya muestran una forma de confort y estatus laboral del trabajador. Sin embargo, hacia esos años de 1937, el contexto de la forma de construir en México daba un cambio radical y finalizaba una etapa en la forma de construir, -muy a la usanza decimonónica-, en templos, edificios públicos. Por lo que podemos ver múltiples edificaciones en la ciudad fechadas ya en pleno siglo XX, pero de características del siglo pasado, por múltiples razones: por haberse suspendido su construcción durante la Revolución mexicana, principalmente. $Y$ el otro factor, ante la llegada de un gobierno facilitador de muchos apoyos a la creación de vivienda, nueva industria, y la estabilización e impulso de los Sindicatos de trabajadores, quienes lograron dar nuevas prestaciones y espacios de equipamiento a los obreros: este periodo fue el cardenismo (1934-1940), en manos del presidente Lázaro Cárdenas.

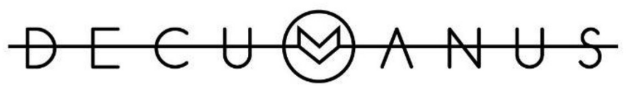

REVISTA INTERDISCIPLINARIA SOBRE ESTUDIOS URBANOS
Núm. 4. Vol. 4. Octubre 2018-Octubre 2019. Instituto de Arquitectura, Diseño y Arte. Universidad Autónoma de Ciudad Juárez. ISSN: 2448-900X 
Imagen 7. Plano de Proyecto de casa habitación para el Agente en la Estación Tres Cumbres. Fechado en 1937.

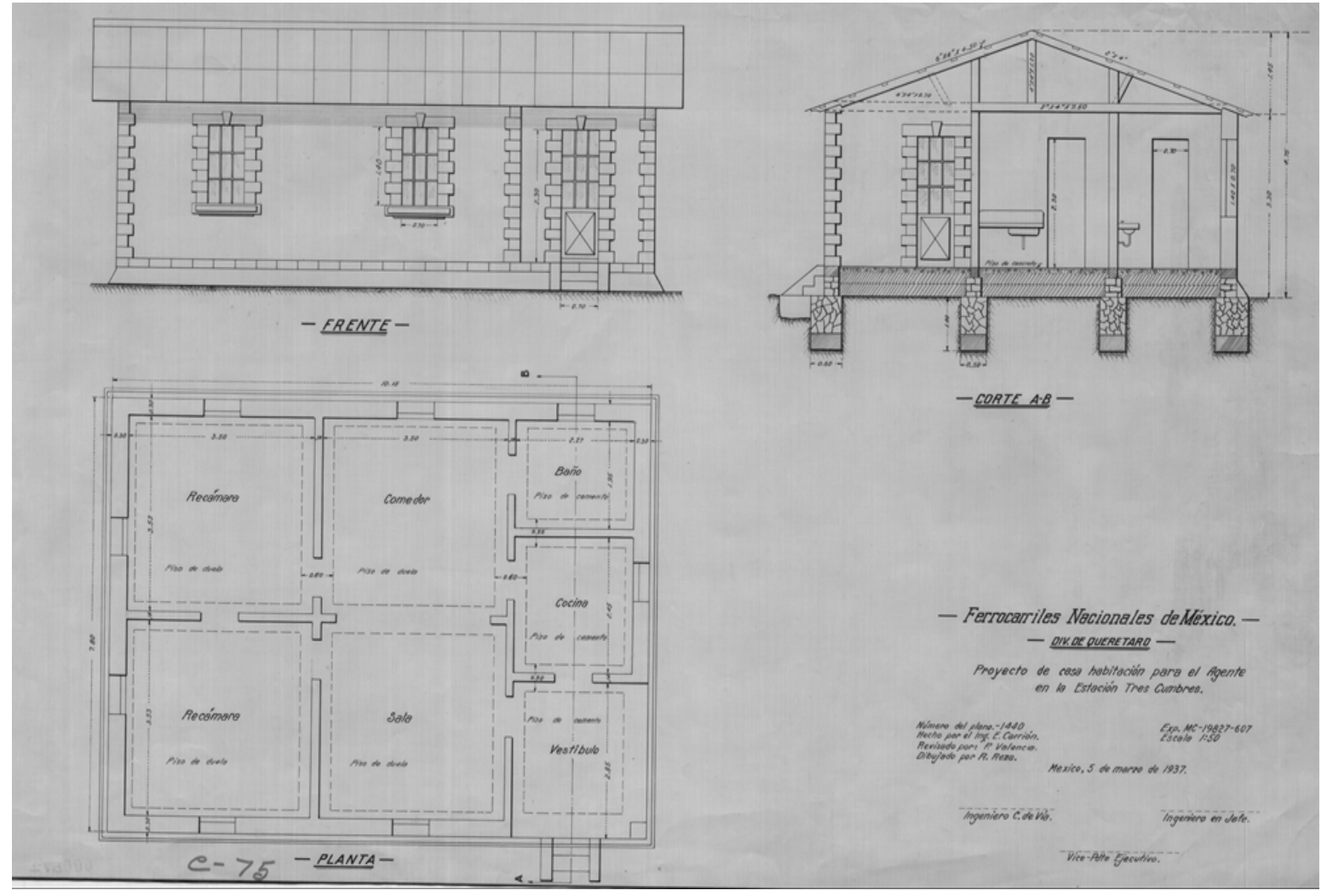

Fuente: Archivo CEDIF-MNFM-Conaculta.

Otro proyecto fechado en ese mismo año de 1937, -como el anteriorfue el Proyecto de casas tipo para el personal de vía (véase imagen 7), que muestran otros valores, a diferencia del anterior. En específico muestra dos tipos de viviendas: Unifamiliares y dúplex. Las primeras, muestran sólo tres espacios, una cocina-comedor, y dos recámaras. La otra muestra una vivienda en condiciones análogas a la anterior, pero con una bodega anexa. Vestibulada por un espacio de acceso, e igualmente en el anterior. Los materiales los podemos ver mediante el uso ya de un cambio radical, mediante el uso de pisos de cemento o ladrillo, muros de tabique de $15 \mathrm{~cm}$, techos de concreto o ladrillo, 2 capas imitando teja (según datos del mismo plano). Lo expresivo-formal, estaba constituido por una serie de elementos, ya dentro del esquema de lo moderno. Podemos apreciar el uso de ventanas horizontales, que fueron viéndose como más comunmente dentro del siglo Xx. Además, podemos ver que las condiciones de los acabados son con base en aplanados de cemento-arena antagónicos, al uso de materiales vistos muy usado en la arquitectura decimonónica industrial (ver imagen 8).

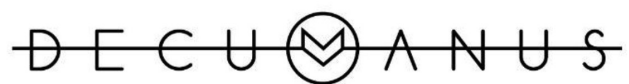

REVISTA INTERDISCIPLINARIA SOBRE ESTUDIOS URBANOS 
Imagen 8. Plano de Proyecto de casas tipo para el personal de vía. Fechado en 1937.

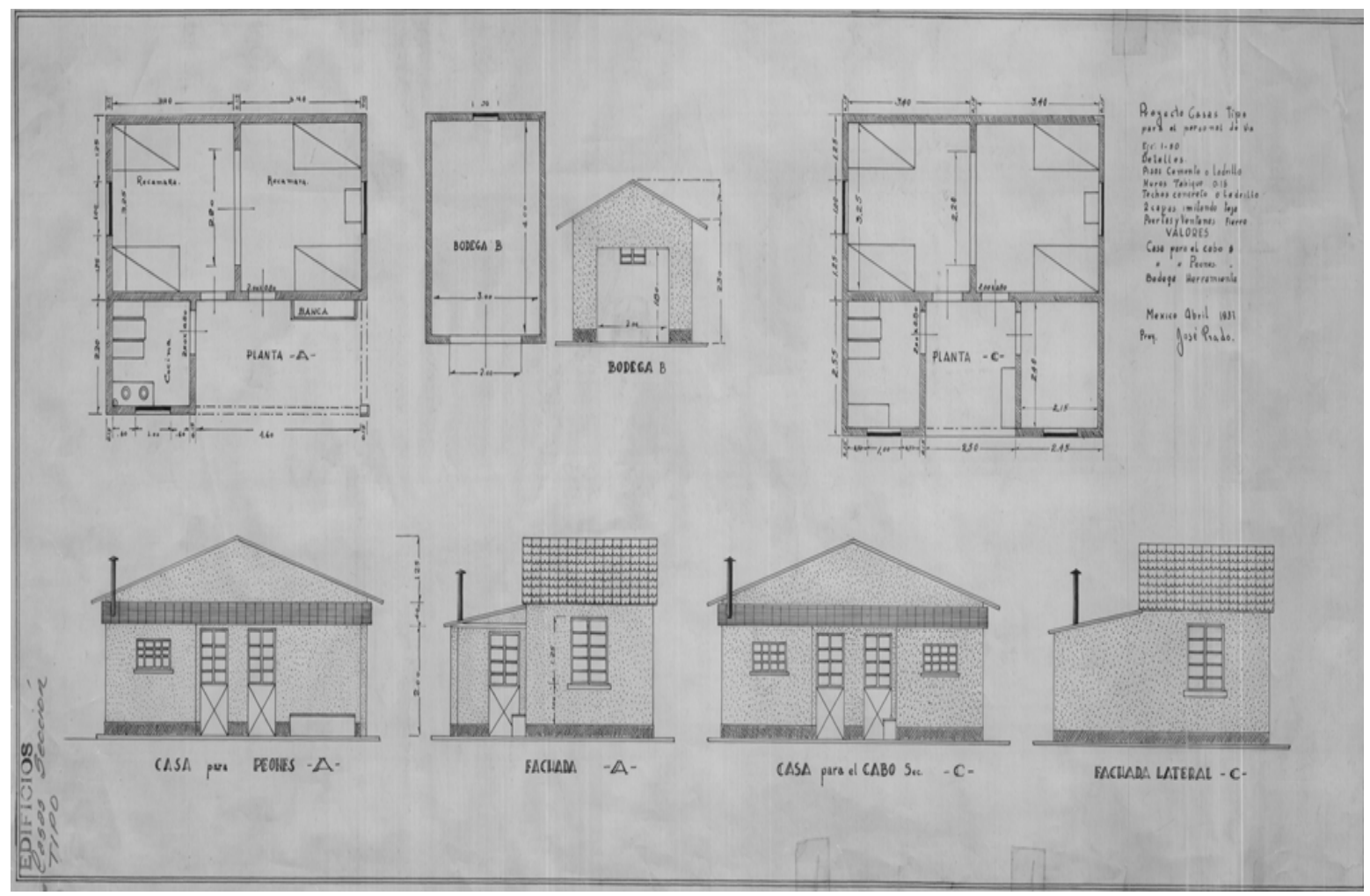

Fuente: ídem

\section{Tipología}

Recapitulando, sobre el tema en cuestión podemos comprender que la vivienda de los trabajadores del ferrocarril no fue la misma en todos los casos, las hubo siguiendo los modelos empleados durante el siglo XIX, hasta las vanguardias durante el siglo $\mathrm{xx}$. Lo ejemplificado permitió comprenderlo, además reconocer los materiales, emplazamientos y elementos que definieron lo formal.

Los factores que resumen las condiciones de la tipología, no son nuevos, y aunque han tomado diversos nombres, son muy similares. Ya que desde épocas pasadas, en especial, desde la era romana, se comenzó a plantear una forma de acercamiento para reconocer los factores o cualidades de la arquitectura. Marcus Lucius Vitrubius pensaba en la firmitas (firmeza), venustas (belleza) y utílitas (utilidad). En tiempos actuales, en específico en las escuelas o facultades de Arquitectura, ya desde hace algunos años, posiblemente desde los años ochenta básicamente partiendo de los apuntes de clase fundamentados en algunos trabajos del arquitecto Rodolfo Gómez Arias de la Universidad Nacional Autónoma de México (UNAM)-, con ello, como apuntes fundamentales para comprender su tipología se ubicaban en el análisis de igualmente tres factores: uso, expresivo y constructivo-estructural. Aunque múltiples valores se desprendían de ellos. Dentro del pri-

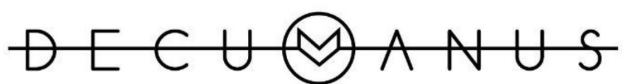

REVISTA INTERDISCIPLINARIA SOBRE ESTUDIOS URBANOS 
mer factor, se analizaba el espacio y su funcionalidad; lo expresivo, pensando en sus valores estéticos, comunicativos; y lo constructivo-estructural, que equivalía a considerar la forma en que se resolvieran todos esos procesos que conforman el soporte y médula principal de resistencia y uso de materiales y sistemas constructivos.

Fernando Tudela (s. f.) aproximadamente en los años ochenta, consideró sobre la tipología: "La primera alusión moderna a la tipología arquitectónica, la hallamos en el siglo pasado en la obra del teórico francés Quatremére de Quincy, quien manifestaba que la palabra 'tipo' no representa tanto la imagen de una cosa que deberá copiarse o imitarse perfectamente como la idea de un elemento que debe de servir de regla o modelo" (p. 4).

El otro gran periodo marcado dentro del siglo Xx fue el llamado como la Modernidad, palabra relativa a lo llamado moderno si la entendemos, según el DLE como: “Del lat. Modernus, de hace poco reciente. 1 adj. Perteneciente o relativo al tiempo de quien habla o a una época reciente". Si bien, esta definición demasiado amplia, y poco clara, que hace alusión -a lo que puede considerarse reciente-, pero en la arquitectura y urbanismo esta palabra toma un sentido especial, ya que se ubica dentro de la historiografía para denotar a la producción que usa como singular elementos en su conformación nuevos sistemas constructivos, por lo tanto, con nuevas tipologías, entre ellas la simpleza en las formas, en general carente de ornamentación y gran importancia a la función. A lo que Sullivan, con su famosa frase enfatizó: "La función sigue a la forma". A esta carac- terización se puede incluir la conformación de otros dos grandes periodos: "la primera y segunda modernidad".

sin embargo, la modernización en los ferrocarriles no solo era arquitectónica, sino, como lo considera Alfredo Nieves del Museo Nacional de los Ferrocarriles de México (MNFM): los Ferrocarriles Nacionales de México en distintas épocas, tuvieron cambios, y se considera dentro ellos a la modernización como: a) La fusión de compañías ferrocarrileras para conformar Ferrocarriles Nacionales de México; b) el cambio de equipo y maquinaria, producto de innovaciones tecnológicas; $c$ ) el cambio de sistemas de trabajo, d) la modificación en el ámbito contractual, y e) el concesionamiento de servicios y bienes a la iniciativa privada.

Desde las primeras viviendas de los trabajadores del ferrocarril en México, la presencia del uso de materiales y sistemas constructivos influenciados por la Revolución Industrial se pudo ver un aspecto muy común en su arquitectura, y en ellos el uso del ladrillo, o quizá la piedra, pero siempre acompañados de cubiertas de metal, estructuras de madera y también de origen metalífero. Esto inclusive hasta entrado el siglo xx y aún con la presencia en diversas latitudes de la modernidad, que había sido una de las fases más prolíficas en el urbanismo y la arquitectura veintera.

\section{Vivienda de los ferrocarrileros en la ciudad de Puebla}

Por otra parte, en la periferia de la ciudad fundada en 1531, Puebla, en el estado del mismo nombre, y capital, al igual que otras muchas en el mundo,

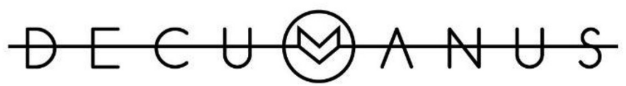

REVISTA INTERDISCIPLINARIA SOBRE ESTUDIOS URBANOS 
Imagen 9. Plano de Estación Nueva, Patio General-Patio de la Ciudad de Puebla.

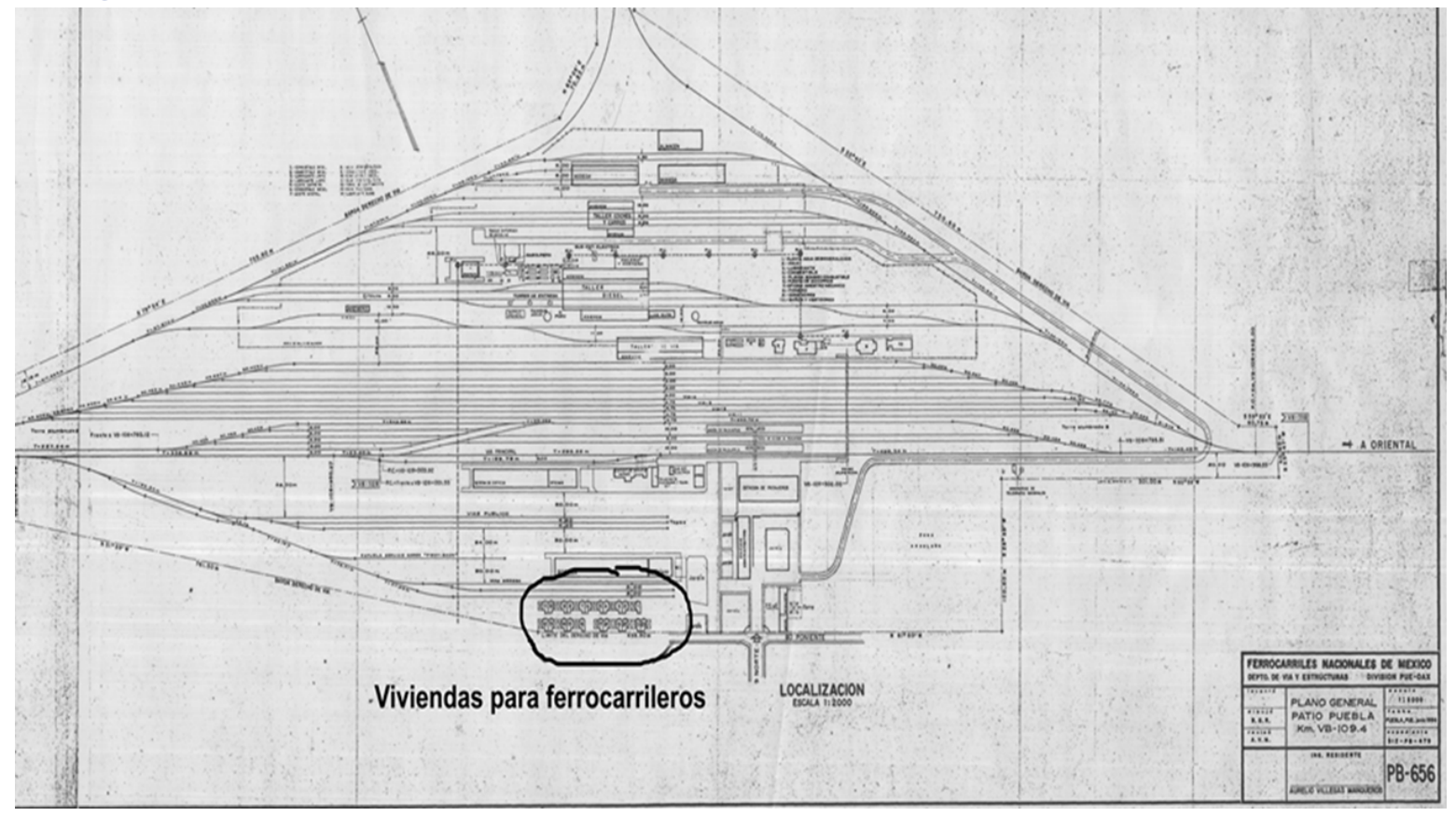

Fuente: Plano de Ferrocarriles Nacionales de México, 1984. Archivo CEDIF-MNFM-Conaculta.

no tuvieron otra gran influencia y ampliaciones urbanas hasta la llegada de las secuelas de la Revolución Industrial que creó asentamientos en las periferias de la ciudad para alojar a las fábricas o conjuntos textiles, o para ubicar estaciones del ferrocarril y vialidades para su recorrido (los caminos de fierro); así, la ciudad, vio el nacimiento de conjuntos que se fueron ampliando y fusionando con la ciudad, hasta ser parte de ella, desterrando, en algunos casos la existencia de lugares rurales entre la ciudad y el campo.

En ese sentido, otro de los componentes en esos conjuntos destinados a la industria $y$, en este caso de los ferrocarriles del transporte, se vio la vivienda, en algunos casos como la ya planteada en este documento, hasta la que se instaló en la segunda mitad del siglo xx correspondiente a la llamada segunda modernidad como el caso del conjunto habitacional anexo a la Estación Nueva del Ferrocarril al norte de la ciudad de Puebla (véase imágenes 9, 10, 11).

Imagen 10. Vista actual de las viviendas de los Ferrocarrileros de la Estación Nueva de Puebla

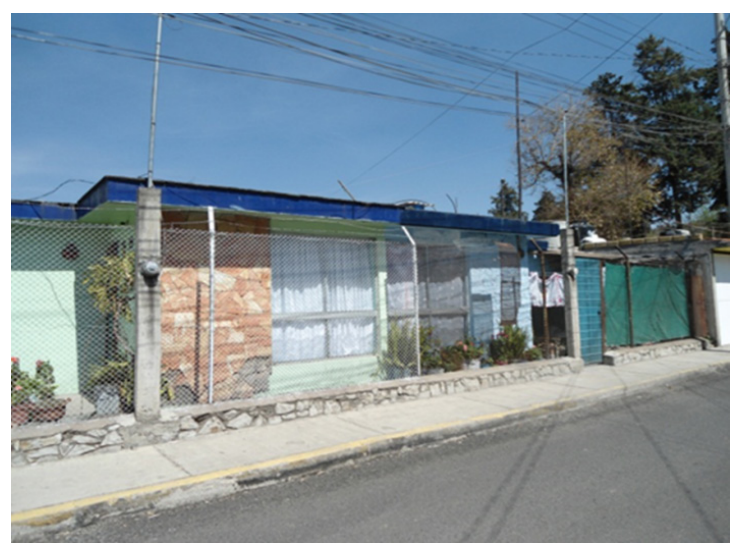

Fuente: Foto ASH/2012

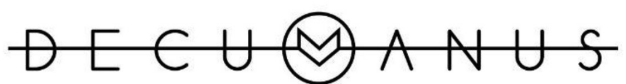

REVISTA INTERDISCIPLINARIA SOBRE ESTUDIOS URBANOS 
Imagen 11. Vista actual del conjunto.

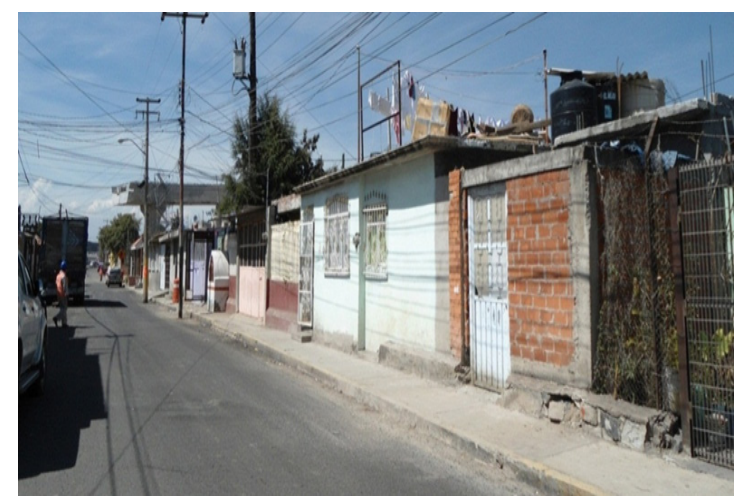

Foto: ASH/2012

Además de otro tipo de vivienda destinada a los ferrocarrileros, que puede incluirse en las condiciones de "interés social" como el caso del conjunto habitacional, es el de Los Ídolos. Ubicada en la parte oriente de la ciudad que dio alojamiento a diversos tipos de empleados, entre ellos, aún burócratas del ferrocarril, mediante un diseño de espacios mínimos (véase imagen 12) y que responden a una tipología simple que empleó un diseño desde la idea de los "espacios mínimos", resueltos en los años ochenta, exponiendo fachadas por igual, con dimensiones mínimas, ventilación e iluminación mínima en los vanos y aún las puertas estandarizadas de condiciones de bajo costo. Esto permite encontrar la existencia de destinos sociales, según el rango al que pertenecen los trabajadores.
Imagen 12. Los Ídolos, estado actual.

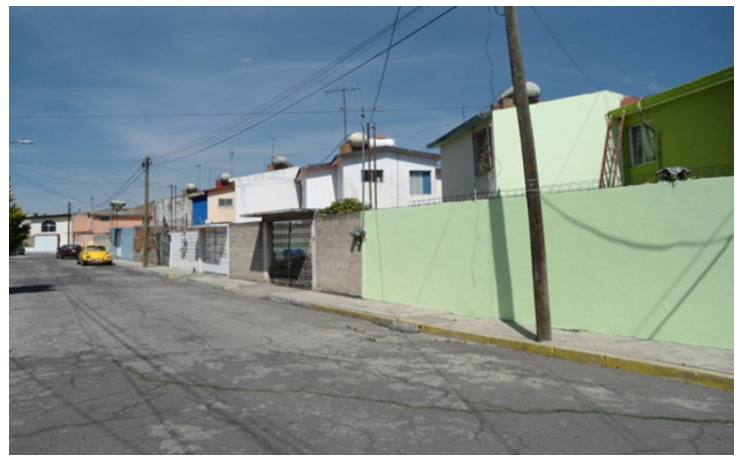

Fuente: Foto ASH/2012

Los factores determinados para la dotación de viviendas variaban, estaban definidos mediante las condiciones laborales dentro de la empresa, por lo tanto, dependía también del estatus de cada trabajador. Inclusive, obedecía a la época o condiciones de pertenencia en determinada empresa de los propios ferrocarriles. En ese contexto se otorgaron:

1) Viviendas para trabajadores de vía,

2) para trabajadores de los talleres, generalmente en los patios de las estaciones,

3) para empleados de oficina,

4) viviendas para directivos.

\section{Modalidades de vivienda}

Las generalidades tipológicas dependieron de estas condiciones, permitiéndoles ubicarse en determinados lugares urbanos o rurales, y fueron los siguientes:

1) Unidad de habitantes del patio de ferrocarriles en los lugares cercanos a estaciones o talleres,

2) colonias nuevas creadas exprofeso, con diseños y tipos de predios 
- con ciertas comodidades urbanas- $y$,

3) las de interés social, que fueron dadas a los trabajadores una vez que la empresa se separó del IMSS (Instituto Mexicano del Seguro Social) y pasó a formar parte del Infonavit (Instituto de Fomento Nacional de Vivienda de los Trabajadores).

\section{Conclusiones}

La generalidad comparativa de este estudio permitió acercarnos a conocer algunos aspectos poco conocidos en el tema de la vivienda de los trabajadores ferrocarrileros. Seguramente existen otros modelos más en México, y en otros países. Pero, como un primer acercamiento para comprender su tipología, permitió abrir un nuevo panorama relacionado con estudios desde la disciplina de la arquitectura, la historia y la propia cultura ferrocarrilera, perteneciente al patrimonio industrial.

La vivienda de este tipo de trabajadores tuvo diversas tipologías que fueron resolviendo sus necesidades. Muchas de ellas se realizaron siguiendo los materiales y sistemas constructivos empleados en los conjuntos, hoy sitios culturales industriales. Vistos en las estaciones, talleres, y equipamiento relacionado al conjunto, donde se emplearon sistemas constructivos, como el uso de piedra braza natural, como elemento estético, con marcos y dinteles de puertas y ventas con piedra dentada todos ellos, muy característicos en el siglo XIX. Asimismo, se pudieron emplear cubiertas de estructura de madera con cubiertas de lámina, por lo general de zinc.
Algunas otras fueron empleando elementos y materiales propios de la "modernidad", ya entrado el siglo xx. A la vez de usar materiales como muros de ladrillo rojo, y un material que marcaría el rumbo de las construcciones durante todo un siglo y aún el presente: el concreto armado. Con lo que podemos comprender que, la vivienda de los trabajadores tuvo además de diversidad ante los "privilegios" de estatus laboral, mejores condiciones en algunas y espacios reducidos en otras. Además, la vivienda de los ferrocarrileros fue evolucionando y mostrándose en varios rumbos. Con los logros de los sindicatos y los cambios sociales y laborales, después de la Revolución mexicana, muchos de los aspectos del país se replantearon y dieron un cambio radical. Por ello, algunos de los trabajadores, muchos de ellos, quizá jubilados, pudieron tener una vivienda con los nuevos programas de vivienda de interés social. Por lo que la conservación del patrimonio de la cultura ferrocarrilera, debe de considerar dentro sus políticas de rescate y defensa a los citados lugares, como parte de los sitios, o conjuntos, muchos de ellos, como sitios mixtos en conjugación con lo natural, o los paisajes típicamente ferrocarrileros.

Muy difícil la labor de la conservación en un país donde existe poco arraigo a este tipo de evidencias. Se trata de valorar y difundir que también es parte del patrimonio y que sin duda, las condiciones de sus restos deben de contemplarse, pero también reutilizarse para generaciones presentes y futuras. La esperanza en una sociedad posmoderna permite comprender que exista una valoración por los grupos

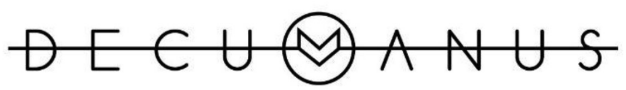

REVISTA INTERDISCIPLINARIA SOBRE ESTUDIOS URBANOS 
que admiran el pasado. Pero, la mayor labor está en los que no lo aprecian.

Muchos son los ejemplos de tipos de vivienda para los ferrocarrileros que han sido adaptadas a las condiciones de los materiales usados en estaciones y talleres entre los que se pueden identificar los siguientes aspectos como una constante.

1. La tipología, puede mostrarse muy diversa, mostrándose con condiciones de uso de materiales diversos.

2. Se puede identificar las condiciones de los efectos de la Revolución, en una primera etapa.

3. Se puede identificar en una segunda etapa, que se pudo ver hasta entrado el siglo $\mathrm{xx}$, para ver dentro de ella, las condiciones de uso de materiales y una estética propia del siglo XIX.

4. Se fueron realizando tipologías de la vivienda también con base en la modernidad que caracterizó a la primera y segunda modernidad.

5. Hasta encontrar condiciones típicas dentro del "interés social", una vez el sindicato tomo varias acciones para mejorar las condiciones de sus trabajadores.

\section{Referencias}

\section{Bibliografía}

CILAC (1996). Villages ouvriers, utopié or realité, Memorias. CILAC, Francia.

Comité Internacional para la Conservación del Patrimonio Industrial (2013). "Carta de Nizgnhy Tagil". Recuperado de http://www.ticcih.org/documents

Comité Internacional para la Conservación del Patrimonio Industrial (2018). “Carta de Sevilla". Recuperado de http://www. icomos.org/chartes

Comité Internacional para la Conservación y Defensa del Patrimonio Industrial (2019). La Carta de Sevilla del Patrimonio Industrial. Un documento imprescindible de estudio y debate para la activación patrimonial. Recuperado de http://ticcih.es/ la-carta-de-sevilla-del-patrimonio-industrial-un-documento-imprescindible-de-estudio-y-debate-para-la-activacion-patrimonial/.

Consejo Internacional de Monumentos y Sitios (2011). "Carta de Dublin". Recuperado de http://www.icomos.org/ chartes

Ebergenyi Magaloní, Ingrid (1986). Primera aproximación al estudio del sindicalismo ferrocarrilero en México, 1917-1936. México. Ciudad de México: Instituto Nacional de Antropología e Historia.

Gisbert Vivó, Matías (2015). “Las viviendas inherentes a las estaciones de ferrocaril de vía estrecha en Valencia en la época de su construcción". En Álvarez Areces, Miguel. Vivienda obrera en la ciudad industrial del siglo xx. Gijón, Asturias, España: TICCIH/CICEES (pp. 223-228).

Gómez Pérez, J. Ramón (2004). “Exploración arqueológica en tres estaciones antiguas ferroviarias de la Ciudad de Puebla". Diverciudades, 12, Benemérita Universidad Autónoma de Puebla, Facultad de Filosofía y Letras, Centro de Estudios de la Ciudad.

Tudela, Fernando (s. f.). Tipología Arquitectónica (Colección Diseño). Puebla, Puebla: FABUAP.

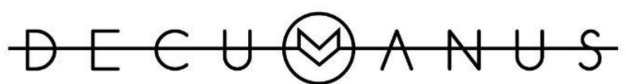

REVISTA INTERDISCIPLINARIA SOBRE ESTUDIOS URBANOS
Núm. 4. Vol. 4. Octubre 2018-Octubre 2019. Instituto de Arquitectura, Diseño y Arte.

Universidad Autónoma de Ciudad Juárez. ISSN: 2448-900X 


\section{Archivos}

Archivo General de Puebla (AGP).

Planoteca del Centro de Documentación e Investigación Ferroviaria, Museo Nacional de los Ferrocarriles Mexicanos del Consejo Nacional para la Cultura y las Artes (CEDIF-MnFM-Conaculta). Fondos vía y estructura.

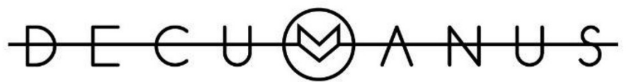

REVISTA INTERDISCIPLINARIA SOBRE ESTUDIOS URBANOS
Núm. 4. Vol. 4. Octubre 2018-Octubre 2019.

Instituto de Arquitectura, Diseño y Arte.

Universidad Autónoma de Ciudad Juárez. ISSN: 2448-900X 